\title{
Thermal energy storage in embankments: Investigation of the thermal properties of an unsaturated compacted soil
}

\author{
Mojdeh Lahoori ${ }^{1, *}$, Sandrine Rosin-Paumier ${ }^{1}$, Yves Jannot ${ }^{1}$, Ahmed Boukelia $^{1,2}$, and Farimah Masrouri ${ }^{1}$ \\ ${ }^{1}$ LEMTA - CNRS UMR 7563, Université de Lorraine, Vandœuvre-lès-Nancy, F-54500, France \\ ${ }^{2}$ ESITC de Metz, Metz, France
}

\begin{abstract}
Thermal energy storage in compacted soils can be considered as a new economically efficient and environmentally friendly technology in geotechnical engineering. Compacted soils are usually unsaturated; therefore, reliable estimates and measurements of their thermal properties are important in the efficiency analysis of these structures. In this study, a method is used to estimate the thermal properties of an unsaturated compacted soil. Several temperature sensors were placed in a thermo-regulated metric scale container to monitor the imposed temperature variation in the range of the 20 to $50{ }^{\circ} \mathrm{C}$. This imposed temperature variation reproduced the temperature variation in the thermal energy storages. An inverse analytical model based on a one-dimensional radial heat conduction equation is used to estimate the thermal diffusivity using the temperature variation between two temperature sensors. The volumetric heat capacity was measured using a calorimeter in the laboratory, enabling the estimation of the thermal conductivity of the compacted soil. Then, this estimated thermal conductivity was compared with the thermal conductivity values measured with two other methods (steady-state and transient-state method). The difference between them are discussed in terms of the sample heterogeneity, sample size, and measurement method.
\end{abstract}

\section{Introduction}

The sun is a renewable source of thermal energy. It provides a relatively clean, abundant and safe source of energy [1]. Various techniques have been developed to store thermal energy of sun during summer in a proper medium to be preserved and later discharged for utilization in the demanded period. Several studies have shown that thermal energy storage in geologic storage media is a pertinent technique [2-4]. A few study deal with the use of compacted soils, due to their appropriate thermal properties and ease of access [5].

In geotechnical engineering, different types of structures are made of unsaturated compacted soil, for example, road, rail embankments and dikes. Generally, these linear structures contain several layers of unsaturated compacted soils. Horizontal heat exchanger loops can easily be installed in these layers during the construction phase [6,7]. The proper design of an embankment to store the thermal energy requires the knowledge of the compacted soil thermal properties to optimize the efficiency of heat storage. The thermal properties that affect the capacity for heat storage are the volumetric heat capacity $\mathrm{C}_{\mathrm{v}}\left(\mathrm{J} \cdot \mathrm{m}^{-3} \cdot \mathrm{K}^{-1}\right)$, the thermal conductivity $\lambda\left(\mathrm{W} \cdot \mathrm{m}^{-1} \cdot \mathrm{K}^{-1}\right)$ and the thermal diffusivity $\alpha$ $\left(\mathrm{m}^{2} \cdot \mathrm{s}^{-1}\right)$. The relationship between these thermal properties is as follow:

$$
\alpha=\frac{\lambda}{C_{v}}
$$

The soil thermal properties depend on its physical and hydro-mechanical properties, such as the mineral composition, degree of saturation and dry density [8-10].
The variation of these properties coupled with the thermal solicitations in unsaturated soil can reach a high level of complexity, which causes difficulties in evaluating the thermal properties of these soils [11-13]. Additionally, in an unsaturated soil, due to such a complex multiphase medium, the heat is transferred by two different modes: conduction through the solid particles, and convection through the gaseous and liquid phases. Due to the complex combination of these phases in unsaturated soil, most of the measurement and estimation methods to evaluate thermal properties are based on the solution of a one-dimensional heat conduction equation assuming a homogeneous soil $[14,15]$.

The steady-state or transient-state methods are two laboratory methods to measure the thermal properties of soils $[16,17]$. On the one hand, the centred hot plate method is a steady-state method that is used to measure the thermal conductivity when the heat transfer flux through the soil sample remains unchanged over time [18]. On the other hand, a transient-state method like thermal needle probe method measures the thermal properties during the unsteady heat transfer process in the laboratory and in the field $[19,20]$. However, the transientstate method only measures a single reading at the corresponding time and cannot measure the temperature profile along the depth of the soil in the field, which is the inherent limitation of this technique [14].

In the field, the thermal diffusivity can also be estimated by temperature monitoring method, using different temperature sensors at different depths in the soil near the surface of the ground $[14,21,22]$. Based on these

\footnotetext{
* Corresponding author: Mojdeh.lahoori@univ-lorraine.fr
} 
methods, different analytical and numerical models were proposed to predict the heat transfer function and consequently the apparent thermal diffusivity of the medium from the observed temperature variations. Gao et al. [23] and Rajeev \& Kodikara [14] used simplified analytical models with the hypothesis of a sinusoidal temperature variation of the soil surface (sinusoidal boundary condition), which is not always validated in thermal energy storage since the duration of the cooling period is not necessary as long as the heating period.

Jannot \& Degiovanni [24] proposed a simple inverse analytical model to estimate the thermal properties of powders or granular materials. In this method, the transfer function is not dependent on the shape and intensity of the heat flux or the external boundary condition (like soil surface in the field). In this temperature/temperature method, first, the transfer function between two recorded temperatures is modelled, and then an associated inverse analytical model is proposed to estimate the thermal diffusivity. In this paper, this analytical model was adapted and applied to estimate the thermal diffusivity of an unsaturated compacted soil, by monitoring the temperature of a large-scale sample when subjected to temperature variation cycles [24]. Then, the volumetric heat capacity, was measured in the laboratory to estimate the thermal conductivity using Eq. (1). This estimated thermal conductivity was compared with other thermal conductivities that were measured in the laboratory with different methods.

\section{Material and methods}

\subsection{Material}

In this study the tested soil was extracted from the Paris region in France. Before being used in the laboratory, the soil is dried, pulverized and sieved through a $2 \mathrm{~mm}$ sieve. A complete characterization of the studied soil was given in Boukelia [25]. The standard Proctor curve of the material [26] showed an optimum water content $\left(\mathrm{w}_{\mathrm{opt}}\right)$ of $16 \%$ and a maximum dry density $\left(\rho_{\mathrm{d}}\right)$ of $1.81 \mathrm{Mg} \cdot \mathrm{m}^{-}{ }^{3}$. This soil is classified as a sandy lean clay, CL, according to the Unified Soil Classification System [27]. The reference compaction state in this study was a water content of $16.3 \%$ and a dry density of $1.72 \mathrm{Mg} \cdot \mathrm{m}^{-3}$.

\subsection{Volumetric heat capacity measurement}

A micro differential scanning calorimeter (DSC, SETARAM $\mu \mathrm{dsc} 3$ ) was used to measure the specific heat $\left(\mathrm{C}_{\mathrm{dry}}\right)$ of dry soil at different temperatures. The specific heat $\left(\mathrm{C}_{\mathrm{p}}\right)$ of soil with a mass water content $(\mathrm{w})$ at $20{ }^{\circ} \mathrm{C}$ can be deduced by:

$$
\mathrm{C}_{\mathrm{p}}=\frac{\mathrm{C}_{\mathrm{dry}}+\mathrm{w}_{\mathrm{water}}}{1+\mathrm{w}}
$$

where $C_{\text {water }}$ is the specific heat of pure water $\left(C_{\text {water }}=\right.$ $4180 \mathrm{~J}^{\mathrm{kg}} \mathrm{kg}^{-1} \cdot \mathrm{K}^{-1}$ at $\left.20^{\circ} \mathrm{C}\right)$. The volumetric heat capacity $\mathrm{C}_{\mathrm{v}}$ $\left(\mathrm{J} \cdot \mathrm{m}^{-3} \cdot \mathrm{K}^{-1}\right)$ is then given by:

$$
\mathrm{C}_{\mathrm{v}}=\rho \mathrm{C}_{\mathrm{p}}
$$

where $\rho$ is the density of the wet soil $\left(\mathrm{kg} . \mathrm{m}^{-3}\right)$.

\subsection{Thermal conductivity measurement}

The thermal conductivity was measured using two different laboratory methods:

Transient-state method: a KD2 Pro Analyser and a single-needle probe (TR-1) with a $2.4 \mathrm{~mm}$ in diameter and $100 \mathrm{~mm}$ in length were used to measure the thermal conductivity [28]. In this method, the heat flux was applied on the upper part of the needle, whereas the temperature measurement was performed on the bottom part of the needle (Figure 1). Tested soil was compacted statically in 3 layers in a standard Proctor mould $(0.116 \mathrm{~m}$ height and $0.101 \mathrm{~m}$ diameter).

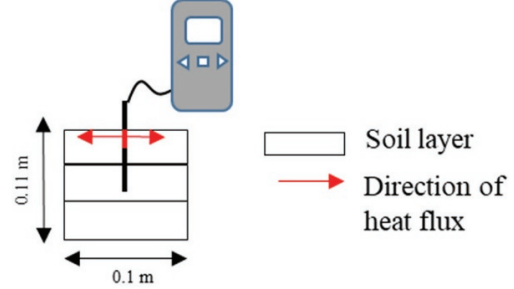

Figure 1: Compacted soil sample for KD2 pro

Steady-state method: the centred hot plate method [29] consists of inserting a thin planar heating element between the soil and a reference material of known thermal conductivity (Figure 2). The temperature of heating element was controlled using a stabilized power supply to keep the $23^{\circ} \mathrm{C}$. The magnitude of power applied was 1747 $\mathrm{W}$. The soil samples were compacted statically in a special mould in a single layer $\left(0.1 \times 0.1 \times 0.02 \mathrm{~m}^{3}\right)$ using a static compaction method. The assembly was inserted between two aluminium plates that were maintained at a constant temperature $\left(\mathrm{T}_{0}=15{ }^{\circ} \mathrm{C}\right)$ and placed in a temperature-controlled climatic chamber $\left(\mathrm{Ta}=23{ }^{\circ} \mathrm{C}\right)$. The equations used to calculate the thermal conductivity are described and explained in Lahoori et al. [30].

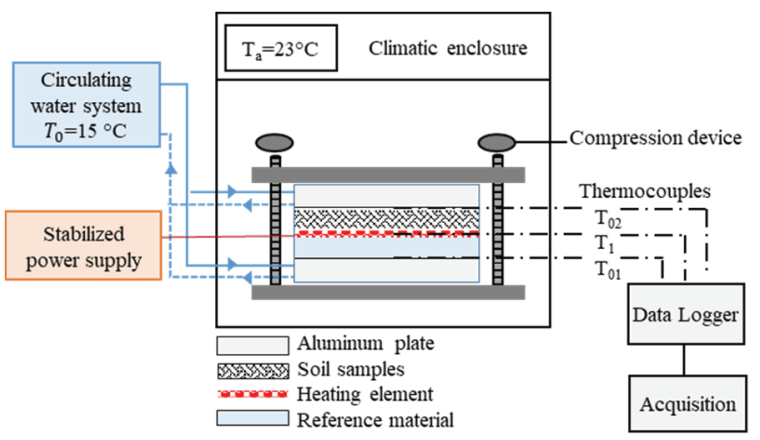

Figure 2: Scheme of centred hot plate device; where $T_{1}$ is the temperature of heating element, $T_{01}$ and $T_{02}$ are temperatures of the aluminum plates and $T_{a}$ is the temperature of the air.

\subsection{Temperature-temperature method}

\subsubsection{Sample preparation for temperature monitoring}

To prepare the sample for temperature monitoring, the soil was compacted statically in several layers in a thermo-regulated metric scale container with a height of 
$0.8 \mathrm{~m}$ and a diameter of $0.6 \mathrm{~m}$ using a pneumatic compactor (Figure 3 ). Five temperature sensors, PT100 (6 $\mathrm{mm}$ in diameter and $60 \mathrm{~mm}$ in length), were positioned in different layers of the compacted soil (T3 to T7, Figure 3) and plugged into a data logger to monitor the temperature variation in different layers of the compacted soil. To induce the temperature cyclic variations, an ethylene glycol-water solution was circulated through a stainless steel tube which was welded to the outside of the container (Figure 3). The heat flux was applied over the radial direction. A heating-cooling system heated the soil from 20 to $50^{\circ} \mathrm{C}$ and then cooled it down to $20^{\circ} \mathrm{C}$. Special attention was paid to insulate the container against heat exchange with atmosphere and preserve the initial water content (Figure 3).

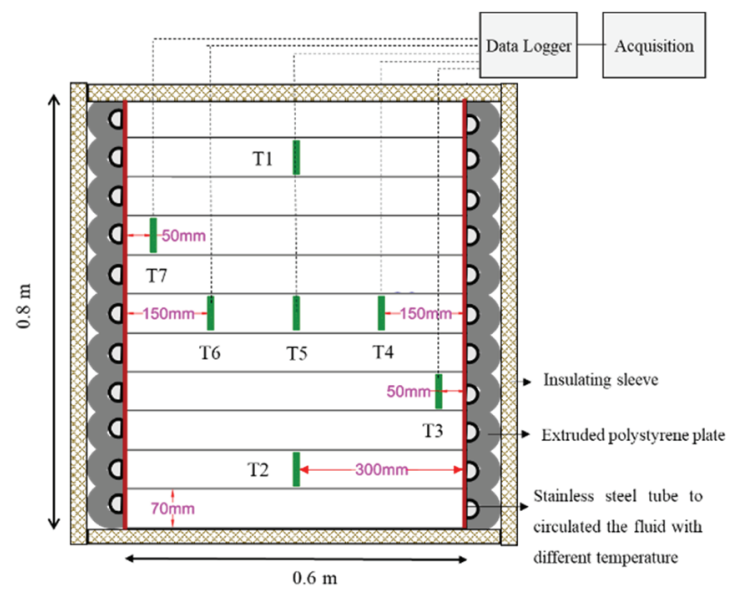

Figure 3: cross sectional view of the thermo-regulated metric scale container and the temperature sensors (T2 to T7).

\subsubsection{Inverse analytical model}

An inverse analytical model based on the onedimensional solution of the Fourier heat balance equation is used to estimate the thermal diffusivity of the compacted soil considering the temperature variations between two temperature sensors. The estimation of thermal diffusivity $\alpha\left(\mathrm{m}^{2} \cdot \mathrm{s}^{-1}\right)$ is based on the transfer function between the inlet and the outlet temperatures [24]. model:

The following hypotheses are considered in this

- the initial temperature of the compacted soil is uniform;

- the heat transfer is $1 \mathrm{D}$;

- the mass transfer is neglected.

The inverse method is expressed by the following equations. The transient heat conduction in the radial direction in cylindrical coordinates is:

$$
\frac{\partial^{2} \mathrm{~T}}{\partial \mathrm{r}^{2}}+\frac{1}{\mathrm{r}} \frac{\partial \mathrm{T}}{\partial \mathrm{r}}=\frac{1}{\alpha} \frac{\partial \mathrm{T}}{\partial \mathrm{t}}
$$

With the boundary conditions

$$
\left\{\begin{array}{l}
\mathrm{T}(\mathrm{r}, \mathrm{t}=0)=\mathrm{T}_{\mathrm{i}} \quad, \quad 0 \leq \mathrm{r} \leq \mathrm{R} \\
\mathrm{T}(\mathrm{R}, \mathrm{t})=\mathrm{T}_{0}(\mathrm{t})
\end{array}\right.
$$

where $\mathrm{T}$ is the temperature $(\mathrm{K}), \mathrm{r}$ is the radius $(\mathrm{m})$ (the distance of the temperature sensors from the axis of the container), $\alpha$ is the thermal diffusivity $\left(\mathrm{m}^{2} \cdot \mathrm{s}^{-1}\right), \mathrm{t}$ is the time $(\mathrm{s}), \mathrm{R}$ is the radius of the container $(\mathrm{m})$ and $\mathrm{T}_{\mathrm{i}}$ is the initial temperature of the sample $(\mathrm{K})$.

$$
\text { Setting: } \quad \overline{\mathrm{T}}=\mathrm{T}-\mathrm{T}_{\mathrm{i}} \text {, }
$$

The Laplace transform of Eq. (4) leads to Eq. (8), where $\mathrm{P}$ is the Laplace parameter $\left(\mathrm{s}^{-1}\right), \theta(\mathrm{r}, \mathrm{p})$ is the Laplace transform of $\overline{\mathrm{T}}(\mathrm{t})$ and $\alpha$ is thermal diffusivity $\left(\mathrm{m}^{2} \cdot \mathrm{s}^{-1}\right)$ :

$$
\frac{\partial^{2} \theta}{\partial \mathrm{r}^{2}}+\frac{1}{\mathrm{r}} \frac{\partial \theta}{\partial \mathrm{r}}=\frac{\mathrm{p}}{\alpha} \theta
$$

This equation may also be written as:

$$
\frac{\partial^{2} \theta}{\partial \mathrm{u}^{2}}+\frac{1}{\mathrm{u}} \frac{\partial \theta}{\partial \mathrm{u}}=\theta \text { with: } \mathrm{u}=\sqrt{\frac{\mathrm{p}}{\alpha}} \mathrm{r}=\mathrm{qr}
$$

The general solution of this equation is [29]:

$$
\theta(\mathrm{r}, \mathrm{p})=\mathrm{AI}_{0}(q r)+\mathrm{BK}_{0}(\mathrm{qr})
$$

where $\mathrm{I}_{0}$ is the modified Bessel function of the first kind of order $0, \mathrm{~K}_{0}$ is the modified Bessel function of the second kind of order $0, \mathrm{~A}$ and $\mathrm{B}$ are constants.

The heat flux is null for $r=0$ so $B=0$ since $\lim _{\mathrm{r} \rightarrow 0} \mathrm{~K}_{0}(\mathrm{qr})=0$.

Hence: $\quad \theta(r, p)=\mathrm{AI}_{0}(\mathrm{qr})$

The Laplace transform $\mathrm{H}_{\mathrm{p}}$ of the transfer function $\mathrm{F}(\mathrm{t}, \alpha)$ $\left(\mathrm{s}^{-1}\right)$ between two temperatures $\overline{\mathrm{T}}\left(\mathrm{r}_{2}\right)$ and $\overline{\mathrm{T}}\left(\mathrm{r}_{1}\right)$ with $\mathrm{r}_{2}>$ $r_{1}$ is:

$$
H_{p}=\frac{\theta\left(r_{2}, p\right)}{\theta\left(r_{1}, p\right)}=\frac{I_{0}\left(q_{2}\right)}{I_{0}\left(q_{1}\right)}
$$

This function only depends on the thermal diffusivity.

$$
\begin{gathered}
\theta\left(\mathrm{r}_{1}, \mathrm{p}\right)=\frac{\mathrm{I}_{0}\left(\mathrm{qr}_{1}\right)}{\mathrm{I}_{0}\left(\mathrm{qr}_{2}\right)} \theta\left(\mathrm{r}_{2}, \mathrm{p}\right) \\
\overline{\mathrm{T}}\left(\mathrm{r}_{1}, \mathrm{t}\right)=\mathcal{L}^{-1}\left[\frac{\mathrm{I}_{0}\left(\mathrm{qr}_{1}\right)}{\mathrm{I}_{0}\left(\mathrm{qr}_{2}\right)}\right] \otimes \overline{\mathrm{T}}\left(\mathrm{r}_{2}, \mathrm{t}\right)
\end{gathered}
$$

where $\otimes$ is the convolution operator.

The thermal diffusivity $\alpha$ is estimated by minimizing the sum of the squared differences between the experimental curve $\overline{\mathrm{T}}\left(\mathrm{r}_{1}\right)$ and the modelled curve calculated by a relationship of the type:

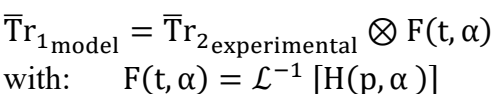

The minimization of the sum of the squared deviations is carried out with the Levenberg-Marquart algorithm, and the function $F(t, \alpha)$ is calculated with the inverse Laplace transform of Eq. (12) and the De Hoog algorithm [31]. As indicated in Eqs. (14) and (15), this analytical model depends on the thermal diffusivity and the transient temperature variations at distances $r_{1}$ and $r_{2}$ from the axis of the cylindrical sample. The temperature variations at different distances from the centre of the container were obtained from the experiment carried out in the laboratory.

\section{Results}

\subsection{Thermal properties measurement using laboratory method}

The dry specific heat, $\mathrm{C}_{\mathrm{dry}}$ of the dry material as a function of the temperature was measured with a microcalorimeter. Then, considering the initial water content $(16.3 \%)$ of the tested samples, the specific heat of the soil was calculated at $20^{\circ} \mathrm{C}$ using Eq. (1): $\mathrm{C}_{\mathrm{p}}=1322 \mathrm{~J} \cdot \mathrm{kg}^{-1} \cdot \mathrm{K}^{-1}$. 
The volumetric heat capacity evaluated was finally calculated using Eq. (3). $\mathrm{C}_{\mathrm{v}}=2.64 \times 10^{6} \mathrm{~J} \cdot \mathrm{m}^{-3} \cdot \mathrm{k}^{-1}$.

The thermal conductivity of the two samples was measured with the needle-probe device (KD2 pro). The average thermal conductivity of the samples was approximately $2.46 \mathrm{~W} \cdot \mathrm{m}^{-1} \cdot \mathrm{K}^{-1}$ (Table 1 ).

Two tests were performed with the centred hot plate method (Figure 2). The first test lasted 2 days, and the second test lasted 6 days. $\mathrm{T}_{1}$ denotes the temperature of the heating element controlled by the electrical intensity. During the tests, the temperature of the heating element $\left(\mathrm{T}_{1}\right)$ was $24.3 \pm 0.76{ }^{\circ} \mathrm{C}$, and the temperature of the aluminium plate $\left(\mathrm{T}_{01}\right)$ was $14.5 \pm 0.5^{\circ} \mathrm{C}$. The temperature difference between the heating element and the aluminium plate induced a one-dimensional heat flow from the heating element through the sample towards the aluminium plate. The temperature of the surrounding air in all the tests was kept constant at $23{ }^{\circ} \mathrm{C}$ to ensure $1 \mathrm{D}$ heat transfer in the center of the sample. During the second test, after one day, the thermal conductivity decreased from 2.08 to $2.05 \mathrm{~W} \cdot \mathrm{m}^{-1} \cdot \mathrm{K}^{-1}$. This decrease could be explained by considering the water evaporation under heating, as the sample water content decreased from $16.3 \%$ to $14.66 \%$. The average thermal conductivity of the compacted soil for both tests was $1.97 \mathrm{~W} . \mathrm{m}^{-1} \cdot \mathrm{K}^{-1}$ (Table 1).

Table 1: Thermal conductivity $\boldsymbol{\lambda}\left(\mathrm{W} \cdot \mathrm{m}^{-1} \cdot \mathrm{K}^{-1}\right)$ of compacted soil

\begin{tabular}{cc}
\hline Method & $\lambda . m^{-1} \cdot K^{-1}$ \\
\hline Thermal needle probe & 2.47 \\
Centred hot plate & 1.97 \\
\hline
\end{tabular}

\subsection{Thermal properties estimation by inverse analytical model}

Different temperature sensors were placed in different layers of the compacted soil (Figure 3 ). It should be noted that the initial temperature of the compacted soil was 20 ${ }^{\circ} \mathrm{C}$ and the temperature variation was imposed through the outer lateral surface of the container. Figure 4 shows the temperature records of the temperature sensors $\mathrm{T} 3, \mathrm{~T} 4$, $\mathrm{T} 5, \mathrm{~T} 6$, and $\mathrm{T} 7$. The time to reach equilibrium at $50{ }^{\circ} \mathrm{C}$ is different according to the distance between the temperature sensors and the source of the heat flux. Thus, temperature sensors $\mathrm{T} 7$ and $\mathrm{T} 3$, which were closer to the source, reached equilibrium quicker than the other temperature sensors that were farther away.

Table 2 shows the thermal diffusivity $\alpha\left(\mathrm{m}^{2} \cdot \mathrm{s}^{-1}\right)$ values for each section between 2 temperature sensors $\left(\operatorname{Tr}_{2}\right.$ and $\mathrm{Tr}_{1}$ ). The average amount of thermal diffusivity was $9.6 \times 10^{-7} \mathrm{~m}^{2} \cdot \mathrm{s}^{-1}$. Busby [32] estimates the thermal properties of different types of soils by utilizing a database of soil temperature measurements taken at a depth of $1 \mathrm{~m}$. The range of the thermal diffusivity values $\left(5 \times 10^{-7} \leq \alpha \leq 10^{-6} \mathrm{~m}^{2} \cdot \mathrm{s}^{-1}\right)$ found by Busby [32] was consistent with the thermal diffusivity values determined in this study for soils with similar characteristics.

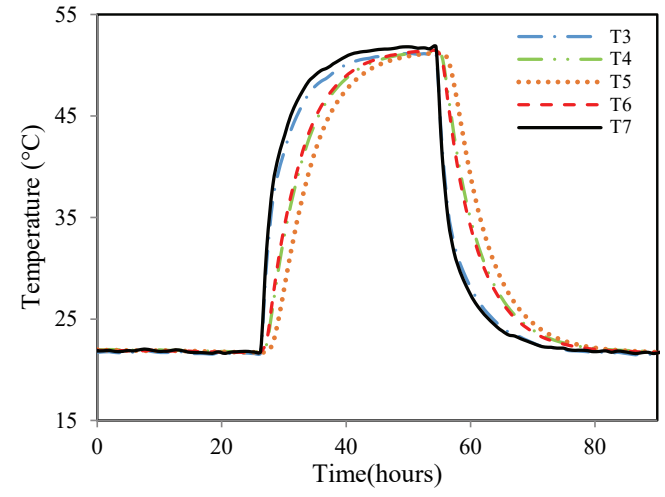

Figure 4: Temperature variations in the compacted soil at various locations in a thermo-regulated metric scale container: heating-cooling cycle $\left(20-50-20^{\circ} \mathrm{C}\right)$.

Table 2: Estimated thermal diffusivity $\alpha$ and thermal conductivity $\lambda$ of compacted soil in the thermo-regulated metric scale container; $r_{1}$ and $r_{2}$ are the distance of the sensors from the axis of the container.

\begin{tabular}{cccccc}
\hline $\mathrm{Tr}_{2}$ & $\mathrm{Tr}_{1}$ & $\begin{array}{c}\mathrm{r}_{1} \\
\mathrm{~m}\end{array}$ & $\begin{array}{c}\mathrm{r}_{2} \\
\mathrm{~m}\end{array}$ & $\begin{array}{c}\alpha \\
10^{-7} \mathrm{~m}^{2} \cdot \mathrm{s}^{-1}\end{array}$ & $\begin{array}{c}\lambda \\
\mathrm{W} . \mathrm{m}^{-1} \cdot \mathrm{K}^{-1}\end{array}$ \\
\hline $\mathrm{T} 3$ & $\mathrm{~T} 4$ & 0.25 & 0.15 & 0.99 & 2.61 \\
$\mathrm{~T} 3$ & $\mathrm{~T} 5$ & 0.25 & 0 & 1.00 & 2.64 \\
T4 & $\mathrm{T} 5$ & 0.15 & 0 & 1.03 & 2.71 \\
T6 & $\mathrm{T} 5$ & 0.15 & 0 & 0.84 & 2.21 \\
T7 & $\mathrm{T} 5$ & 0.25 & 0 & 0.9 & 2.37 \\
T7 & $\mathrm{T} 6$ & 0.25 & 0.15 & 0.93 & 2.45 \\
\hline Average & & & & 9.4 & 2.47 \\
\hline
\end{tabular}

Figure $5 \mathrm{a}$ shows the temperature recorded with the $\mathrm{T} 5$ and $\mathrm{T} 6$ sensors, and Figure $5 \mathrm{~b}$ compares the experimental records with the results of invers analytical model Eq. (15). The residuals which are the difference between measured temperature and values from invers analytical model are much lower than $0.02{ }^{\circ} \mathrm{C}$ for a maximum temperature increase of $27{ }^{\circ} \mathrm{C}$, which shows a good agreement between the experimental measurements and the analytical model results and validates the applicability of the 1D heat conduction model (Figure 5b). Lahoori et al. [30] analysed in detail the sensitivity of this inverse analytical model according to the uniqueness of the solution, the standard deviation of the temperature recorded by the sensors and the errors due to the distance variations of the sensors from the axis of the container.

The volumetric heat capacity $\left(2.64 \times 10^{6} \mathrm{~J} \cdot \mathrm{m}^{-3} \cdot \mathrm{K}^{-1}\right)$ was used to calculate the thermal conductivity $\lambda\left(\mathrm{W} \cdot \mathrm{m}^{-1} \cdot \mathrm{K}^{-1}\right)$ using Eq. (1). The average obtained value was $2.51 \pm 0.23$ $\left(\mathrm{W} \cdot \mathrm{m}^{-1} \cdot \mathrm{K}^{-1}\right)$.

\subsection{Discussion}

The estimated values of the thermal conductivity measured by the inverse analytical model $\left(2.47 \mathrm{~W} \cdot \mathrm{m}^{-1} \cdot \mathrm{K}^{-1}\right)$ and by the transient-state method $\left(2.46 \mathrm{~W} \cdot \mathrm{m}^{-1} \cdot \mathrm{K}^{-1}\right)$ are very close. In contrast, the deviation between the values obtained by the inverse 
analytical model and the centred hot plate method (1.97 W. $\mathrm{m}^{-1} \cdot \mathrm{K}^{-1}$ ) is $20 \%$ lower.
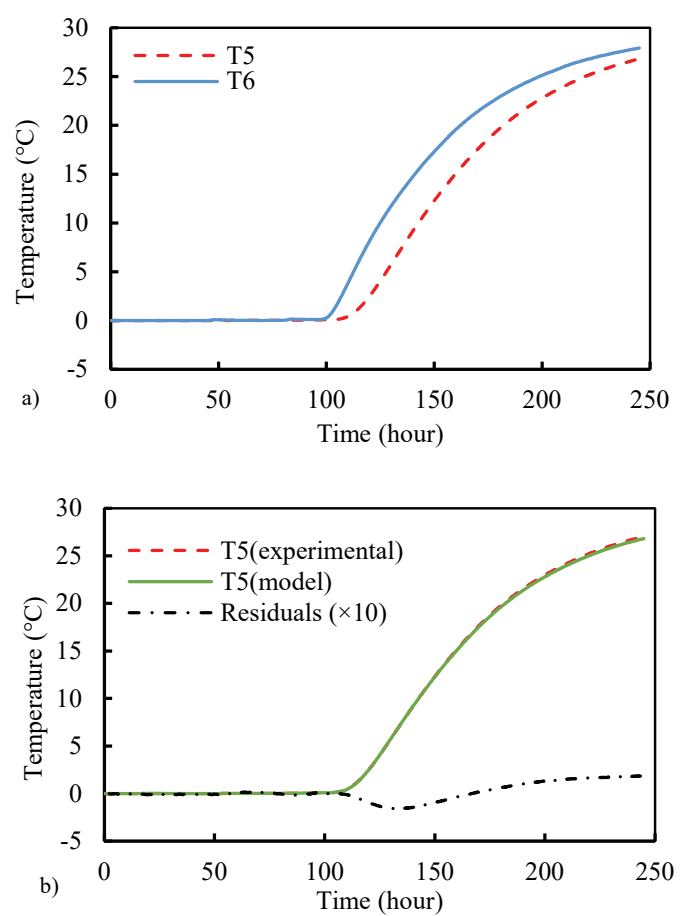

Figure 5: a) temperature evolution recorded by $\mathrm{T} 5$ and $\mathrm{T} 6$ sensors b) comparison between the experimental and the model values for $\mathrm{T} 5$ evolution.

In the compacted soil the heterogeneity plays an important role on the value of the thermal conductivity. The compacted soil is anisotropic, with a higher thermal conductivity in the radial direction $[33,34]$. Due to the sample preparation method, in this study, several layers were statically compacted in order to reach the desired density and homogeneity. The thermal conductivity estimated and measured parallel to the layering (in the metric scale container and with the thermal needle probe) were found to be higher than that measured perpendicular to the layering (in centred hot plate). Therefore, it can be concluded that the soil anisotropy could be an influencing factor on the axial and radial direction measurements.

Other difference between these values originated in measurement methods. In centred hot plate method, the thermal resistance between the heat element and the soil sample is neglected [30]. A thin layer of the air between the soil sample and the heat element, could provide a thermal resistance [35]. Therefore, this thermal resistance reduces the heat flux through the soil sample and consequently reduces the soil thermal conductivity. Also the centred hot plate is a steady state method and the time to reach temperature equilibrium (48 to 144 hours) is higher than transient-state method (10 minutes). During the time consuming test for centred hot plate, the water content decreases. The water plays a bridge role between the soil particles increasing the heat transfer and consequently increasing the effective contact area between the soil particles [36]. As a result, the heat transfer is smaller in the sample with low water content. In the metric scale container, the water content of the compacted soil varied slightly. This condition was close to the transient-state method as the measurement is relatively quick and the initial condition does not change.

The dimension of the samples could also explain these difference. The transient-state and centred hot plate measurements are performed on small-scale samples, whereas the estimated thermal conductivity was calculated from large-scale soil sample. The large-scale samples present more heterogeneity in terms of soil characteristics like mineralogy, granulometry, water content, density. therefore, the measurement values are an average of all these varieties.

In the field, two temperatures sensors can be placed at different distances from the heat exchanger tubes to monitor the temperature variation in an arbitrary cylindrical surface. In that way, the heat transfer will be measured in every direction in order to take into account the heterogeneity of the soil mass. It should be noted that this method is validated for the $1 \mathrm{D}$ heat transfer. Therefore, the temperature monitoring sensors should be placed in the distance lower than the impact area of the other horizontal heat exchanger tubes. For example, if the distance between two heat exchangers is $3 \mathrm{~m}$ the sensors position has to be in an arbitrary cylindrical surface with a diameter lower than $1.5 \mathrm{~m}$. This method could ensure real-time monitoring of possible future applications of thermal energy storage in compacted soils like embankments or other configurations.

\section{Conclusions}

In this study, the thermal properties of an unsaturated compacted soil were investigated. An inverse analytical model was applied on an unsaturated compacted soil to estimate the thermal diffusivity. One of the main benefits of this method is that it only requires the measurement of time series of temperature at two locations. The thermal conductivity was then estimated using the volumetric heat capacity measured by calorimetry. This value was compared with the value obtained with a transient-state method and the results showed a good agreement.

The main advantage of this method is its application for in situ measurements taking into account, the transient heat conduction in the radial direction.

\section{References}

1. B. Stojanović, J. Akander. Build-up and long-term performance test of a full-scale solar-assisted heat pump system for residential heating in Nordic climatic conditions. Applied Thermal Engineering, 30 (2), 188-195 (2010)

2. A.H. Abedin, M.A. Rosen. A critical review of thermochemical energy storage systems. Open Renewable Energy Journal, 4, 42-46 (2011).

3. S. Maghsoodi, O. Cuisinier, F. Masrouri. Thermal effects on mechanical behaviour of soil-structure interface. Canadian Geotechnical Journal, 57(1): 3247 (2019). 
4. T. Başer, J.S. McCartney. Transient evaluation of a soil-borehole thermal energy storage system. Renewable Energy, 147, 2582-2598 (2020).

5. J. Xu, R.Z. Wang, Y. Li. A review of available technologies for seasonal thermal energy storage. Solar Energy, 103, 610-638 (2014).

6. M. Jradi, C. Veje, B.N. Jørgensen. Performance analysis of a soil-based thermal energy storage system using solar-driven air-source heat pump for Danish buildings sector. Applied Thermal Engineering, 114, 360-373 (2017).

7. A. Boukelia, H. Eslami, S. Rosin-Paumier, F. Masrouri. Effect of temperature and initial state on variation of thermal parameters of fine compacted soils. European Journal of Environmental and Civil Engineering, 23 (9), 1125-1138 (2019).

8. E. Penner, G.H. Johnston, L.E. Goodrich. Thermal conductivity laboratory studies of some Mackenzie Highway soils. Canadian Geotechnical Journal, 12 (3), 271-288 (1975).

9. N.H. Abu-Hamdeh, R.C. Reeder. Soil Thermal Conductivity: Effects of Density, Moisture, Salt Concentration, and Organic Matter. Soil Science 1Society of America Journal, 64 (4), 1285-1290 (2000).

10. J. Yao, H. Oh, W.J. Likos, J.M. Tinjum. Three laboratory methods for measuring thermal resistivity dryout curves of coarse-grained soils. Geotechnical Testing Journal, 37(6), 1056-1067 (2014).

11. M.H. Jahangir, M. Ghazvini, F. Pourfayaz, M. H. Ahmadi. A numerical study into effects of intermittent pump operation on thermal storage in unsaturated porous media. Applied Thermal Engineering, 138, 110-121 (2018).

12. T. Başer, Y. Dong, A.M, Moradi, N. Lu, K. Smits, S. Ge, D. Tartakovsky, J.S. McCartney. Role of nonequilibrium water vapor diffusion in thermal energy storage systems in the vadose zone. Journal of Geotechnical and Geoenvironmental Engineering, 144(7), 04018038 (2018).

13. K.M. Smits, T. Sakaki, S. E. Howington, J. F. Peters, T.H. Illangasekare. Temperature ependence of thermal properties of sands across a wide range of temperatures (30-70 C). Vadose Zone Journal, 12(1), vzj2012-0033 (2013).

14. P. Rajeev, J. Kodikara. Estimating apparent thermal diffusivity of soil using field temperature time series. Geomechanics and Geoengineering, 11 (1), 28-46 (2016).

15. N. Ukrainczyk. Thermal diffusivity estimation using numerical inverse solution for 1D heat conduction. International journal of heat and mass transfer, 52 (2526), 5675-5681 (2009).

16. N. H. Abu-Hamdeh, A. I. Khdair, R.C. Reeder. A comparison of two methods used to evaluate thermal conductivity for some soils. International Journal of Heat and Mass Transfer, 44 (5), 1073-1078 (2001).

17. D. Kraemer, G. Chen. A simple differential steadystate method to measure the thermal conductivity of solid bulk materials with high accuracy. Review of Scientific Instruments, 85 (2), 025108 (2014).
18. Y. Jannot, V. Felix, A. Degiovanni. A centered hot plate method for measurement of thermal properties of thin insulating materials. Measurement Science and technology, 21 (3), 03510610 (2010).

19. J. R. Bilskie. Dual probe methods for determining soil thermal properties: Numerical and laboratory study. $\mathrm{PhD}$ thesis, University of Iowa State, Ames, Lowa, United States. 10679 (1994).

20. R. Coquard, D. Baillis, D. Quenard. Experimental and theoretical study of the hot-wire method applied to low-density thermal insulators. International journal of heat and mass transfer, 49 (23-24), 4511-4524 (2006).

21. W.M. Adams, G. Watts, G. Mason. Estimation of thermal diffusivity from field observations of temperature as a function of time and depth. American Mineralogist, 61 (7-8), 560-568 (1976).

22. R. Horton, P.J. Wierenga, D.R. Nielsen. Evaluation of methods for determining the apparent thermal diffusivity of soil near the surface. Soil Science Society of America Journal, 47 (1), 25-32 (1983).

23. Z. Gao, L. Wang, R. Horton. Comparison of six algorithms to determine the soil thermal diffusivity at a site in the Loess Plateau of China. Hydrology and Earth System Sciences Discussions, 6, 2247 (2009).

24. Y. Jannot, A. Degiovanni. Thermal properties measurement of dry bulk materials with a cylindrical three layers device. Review of Scientific Instruments, 84 (9), 094901 (2013).

25. A. Boukelia. Physical and numerical modeling of energy geostructures. $\mathrm{PhD}$ thesis, University of lorraine, Nancy, France, 187 pp (2016).

26. AFNOR. NF P 94-093: Soils: Investigation and testing. Determination of the compaction characteristics of a soil. Standard Proctor test. Association Française de Normalisation, Paris, France, NF P 94-093. Modified Proctor test (p. 18), (1999b).

27. ASTM Standard D2487. "Standard Practice for Classification of Soils for Engineering Purposes (Unified Soil Classification System). ASTM International, West Conshohocken, PA (2000).

28. Devices, D. KD2 pro thermal properties analyzer operator's manual. Pullman, WA (2016).

29. Y. Jannot, C. Moyne. Thermal properties measurements of materials. ISTE Wiley, edition, p. 299 (2018).

30. M. Lahoori, Y. Jannot, S. Rosin-Paumier, A. Boukelia, F. Masrouri. Measurement of the thermal properties of unsaturated compacted soil by the transfer function estimation method. Applied Thermal Engineering, 167, 114795 (2020).

31. F.R. De Hoog, J.H. Knight, A.N. Stokes. An improved method for numerical inversion of Laplace transforms. SIAM Journal on Scientific and Statistical Computing, 3 (3), 357-366 (1982).

32. J. Busby. Determination of thermal properties for horizontal ground collector loops. World Geothermal Congress 2015, 19-25 April, Melbourne, Australia (2015). 
33. K. Midttømme, E. Roaldset, P. Aagaard. Thermal conductivity of selected claystones and mudstones from England. Clay Minerals, 33 (1), 131-145 (1998).

34. J. E. Low, F. A. Loveridge, W. Powrie, D. Nicholson. A comparison of laboratory and in situ methods to determine soil thermal conductivity for energy foundations and other ground heat exchanger applications. Acta geotechnica, 10 (2), 209-218 (2015).

35. Y. Jannot, A. Degiovanni, V. Grigorova-Moutiers, J. Godefroy. A passive guard for low thermal conductivity measurement of small samples by the hot plate method Measurement Science and Technology, 28(1), 015008 (2016).

36. L.A. Salomone, W.D. Kovacs. Thermal resistivity of soils. Journal of Geotechnical Engineering, 110 (3), 375-389 (1984). 